\title{
Anomalously thin transition zone beneath the Galápagos hotspot
}

\author{
Emilie E.E. Hooft ${ }^{\mathrm{a}, \mathrm{b}, *}$, Douglas R. Toomey ${ }^{\mathrm{a}}$, Sean C. Solomon ${ }^{\mathrm{b}}$ \\ a Department of Geological Sciences, University of Oregon, 1272 Cascade Hall, Eugene, OR 97403, USA \\ b Department of Terrestrial Magnetism, Carnegie Institution of Washington, 5241 Broad Branch Rd., NW, Washington, \\ DC 20015, USA
}

Received 12 March 2003; received in revised form 22 August 2003; accepted 8 September 2003

\begin{abstract}
Differential arrival times of P-to-S conversions at 410 and $660 \mathrm{~km}$ depth, measured from radial receiver functions, are used to determine the thickness of the mantle transition zone beneath the Galápagos hotspot. For an area of approximately $700 \mathrm{~km}^{2}$ surrounding the Galápagos archipelago, P660s-P410s times are not significantly different from those for the Pacific Basin. In contrast, a subset of the Galápagos data yields differential times indicating thinning of the mantle transition zone by $18 \pm 8 \mathrm{~km}$ within an area approximately $100 \mathrm{~km}$ in radius centered about 40 $\mathrm{km}$ southwest of the center of the island of Fernandina. This anomaly is consistent with an excess temperature of $130 \pm 60 \mathrm{~K}$ within this volume of the transition zone, comparable to that inferred beneath the Iceland and Society hotspots. The most straightforward interpretation of this anomaly is that a mantle plume upwelling from depths greater than $410 \mathrm{~km}$ underlies the Galápagos hotspot.
\end{abstract}

(C) 2003 Elsevier B.V. All rights reserved.

Keywords: mantle plume; upper mantle transition zone; oceanic hotspot

\section{Introduction}

Hotspot volcanism has been variously attributed to upwelling mantle plumes arising from mantle boundary layers - either from the $\mathrm{D}^{\prime \prime}$ layer at the base of the mantle (e.g., [1-4]) or from the boundary layer at the bottom of the mantle tran-

\footnotetext{
* Corresponding author. Tel.: +1-541-346-4762; Fax: +1-541-346-4692.

E-mail addresses: emilie@newberry.uoregon.edu (E.E.E. Hooft), drt@newberry.uoregon.edu (D.R. Toomey), scs@dtm.ciw.edu (S.C. Solomon).
}

sition zone at $660 \mathrm{~km}$ depth (e.g., [5-7]) - as well as to upper mantle convective instabilities produced by extensional faulting of the lithosphere (e.g., [8,9]) (see [10] for a recent synthesis). At the Azores and Galápagos hotspots, volatile enrichment of the upper mantle is also thought to contribute to excess melt production, thereby reducing the required mantle temperature anomaly [11-13]. Inasmuch as the mantle discontinuities at 410 and $660 \mathrm{~km}$ depth correspond to temperaturedependent phase transitions [14], mapping the depth to these discontinuities can constrain the excess temperature within the transition zone beneath a given hotspot and the extent to which the 
anomaly is consistent with a plume from the lower mantle or with strictly upper mantle processes [15-21].

Recent seismic studies conducted at the Hawaii, Iceland, and Society hotspots support the presence of anomalously hot mantle plumes that originate at depths in excess of 400-700 km [15,17, $18,20,22-25]$. In particular, the arrival times of $\mathrm{S}$-waves converted from teleseismic P-waves at the transition zone discontinuities $[15,17,18,20]$ and underside reflections of $\mathrm{S}$-waves from these discontinuities (SS precursors) [24] indicate a localized thinning of the transition zone, a result consistent with a thermal anomaly and plumelike upwelling. Comparison of the thermal struc- ture beneath the Galápagos with these other oceanic hotspots is particularly interesting for several reasons. Though the most active volcanoes are found in the western Galápagos, volcanism is distributed throughout the archipelago. While high ${ }^{3} \mathrm{He} /{ }^{4} \mathrm{He}$ ratios indicate a contribution from an undegassed mantle source presumably deeper than the asthenosphere [26,27], geochemical anomalies show that volatile enrichment of the upper mantle also contributes to excess melting beneath the Galápagos [11,13].

Here we present observations of the arrival times of P410s and P660s phases, teleseismic $\mathrm{P}$-waves converted to shear waves at the mantle discontinuities at 410 and $660 \mathrm{~km}$ depth, respec-

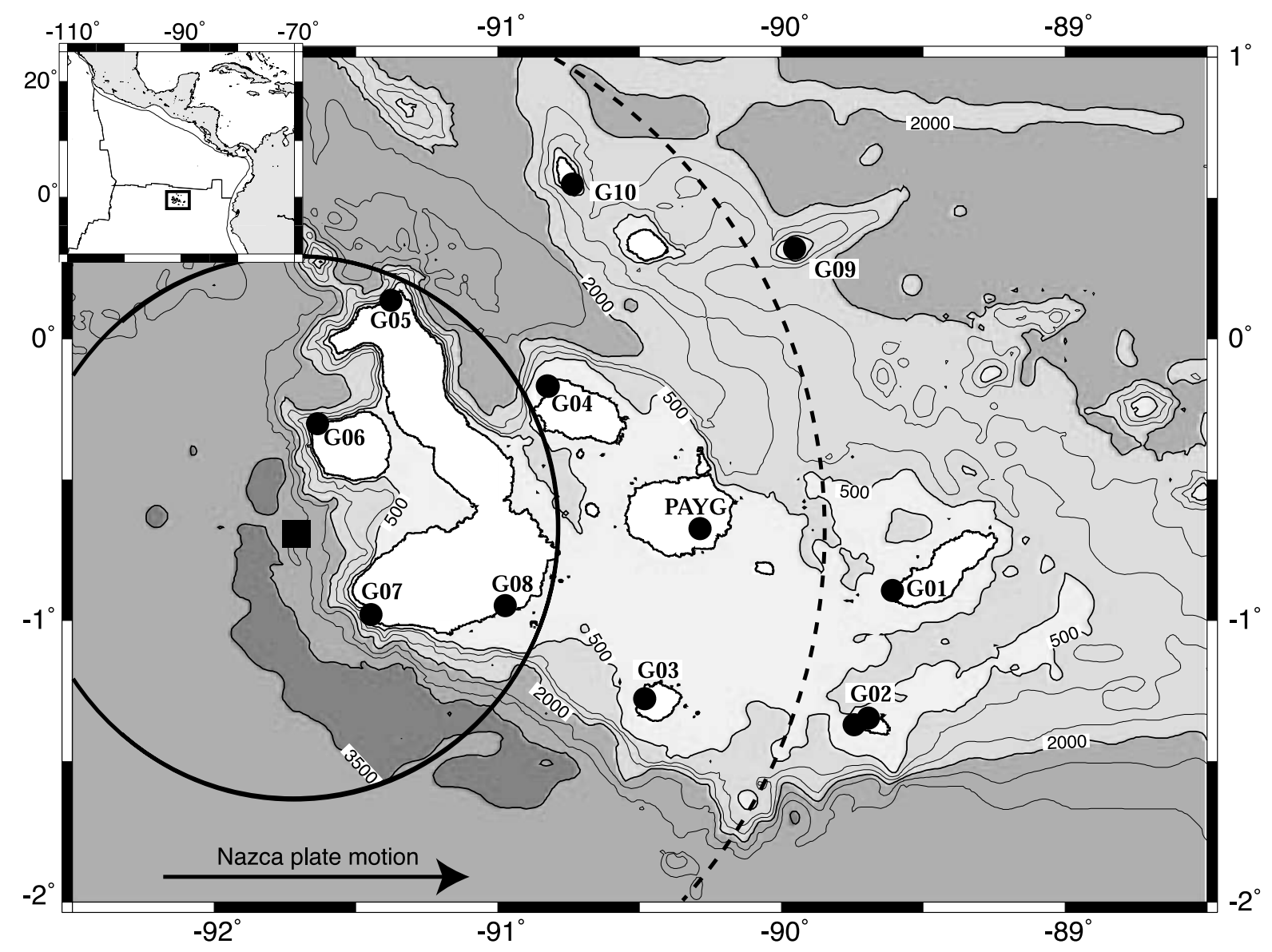

Fig. 1. Location of the Galápagos Islands (see inset) and of the broadband seismic network. PAYG is a permanent GSN station. Bathymetry is depicted at a 500-m contour interval. The approximate center of anomalously thin mantle transition zone (solid square) and circles concentric on this point with radii of $100 \mathrm{~km}$ (solid) and $200 \mathrm{~km}$ (dashed) are also shown (see text). The direction of Nazca plate motion, in the hotspot reference frame [36], is indicated by the large black arrow. 
tively, from a broadband seismic network on the Galápagos Islands. The arrival times, and in particular the differential P660s-P410s times, provide the most robust constraints to date on the mantle thermal structure beneath this hotspot. We find that low-velocity upper mantle and a thinned transition zone underlie the Galápagos. If these characteristics are the result of excess temperature, the thermal anomaly beneath the Galápagos is similar to that inferred beneath the Iceland and Society hotspots and smaller than that beneath Hawaii.

\section{The seismic network}

The network consists of 10 three-component broadband portable seismometers installed in September 1999 and the permanent Global Seismographic Network (GSN) station PAYG (Fig. 1). The array aperture is $300 \mathrm{~km}$ by $200 \mathrm{~km}$, and the station spacing is $50-70 \mathrm{~km}$. The seismic sensors at all the portable stations are Streckeisen STS-2; two Guralp CMG-3ESP instruments were initially deployed but were replaced after the first year. Data loggers were PASSCAL-equivalent Reftek units recording continuously at 20 samples per second. In this paper we utilize data recorded between September 1999 and April 2002.

\section{Receiver function analysis}

We use the teleseismic receiver function method to measure the arrival times of P-to-S conversions from the 410- and 660-km discontinuities [28,29]. The receiver functions are calculated using a water level deconvolution method [29]. The three-component seismic data are rotated into vertical, radial, and tangential components, and the vertical component is deconvolved from the radial component using a water level value of $0.01(0.1,0.05,0.01$, and 0.001 were tested $)$. The direct $\mathrm{P}$-wave amplitude on the radial receiver functions is normalized to unity, and the receiver functions are bandpass filtered from 30 to 100 $\mathrm{mHz}$ using a third-order, zero-phase Butterworth filter.
Examples of radial receiver functions for one event are shown in Fig. 2. The P410s and P660s phases are clear arrivals in many of the individual receiver functions as well as in the stack. The amplitudes of these phases are generally $15-25 \%$ of the direct P-wave amplitude, though the amplitudes and arrival times of these phases vary among stations. The large amplitude of the converted phases, relative to amplitudes synthesized from global models (e.g., [15]), and the observed variations in arrival times are likely due to both random noise in individual receiver functions and relief on the mantle discontinuities that focuses and defocuses the converted phases (e.g., [30]).

We obtain a total of 190 carefully selected receiver functions from records of 54 earthquakes at epicentral distances between $30^{\circ}$ and $150^{\circ}$ for which the P410s and P660s (or PP410s and PP660s) phases were identified. These events have body wave magnitude $M_{\mathrm{b}} \geq 6$ and display P-wave coda uncontaminated by other arrivals having ray parameters significantly different from those of $\mathrm{P}$ or PP. In the remainder of the paper we

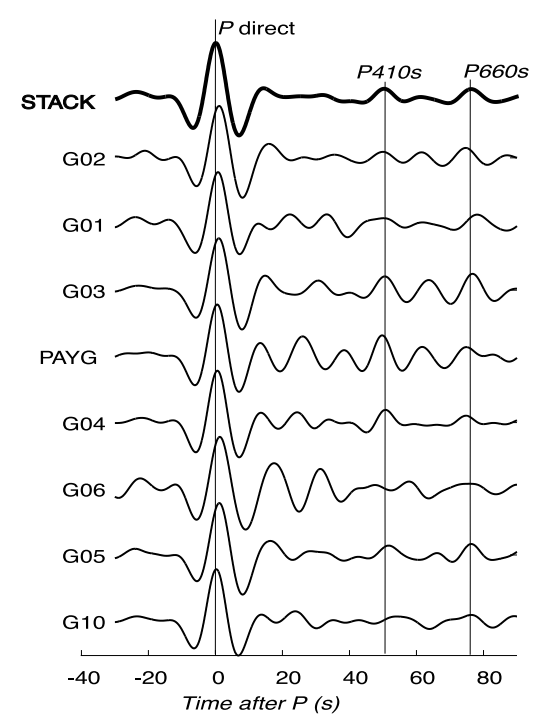

Fig. 2. An example of radial receiver functions at individual stations and a stack for the $\mathrm{P}$ arrival from the $M_{\mathrm{b}} 6.3$, Hector Mine, California, earthquake of 16 October 1999 at an epicentral distance of $114^{\circ}$ and a back azimuth of $325^{\circ}$. The times of the direct arrival and of the P410s and P660s converted phases for the stack are indicated by vertical lines. 
do not distinguish between $\mathrm{P}$ and $\mathrm{PP}$ receiver functions.

To be able to compare the arrival times of the converted phases, we apply normal-moveout corrections to account for path length differences arising from variations in incidence angle, thus projecting all the receiver functions to a common range. Predicted arrivals for the $410-$ and $660-\mathrm{km}$ P-to-S conversions are calculated by ray tracing through the iasp91 model [31] modified to include a $25-\mathrm{km}$-thick crust. Using this predicted moveout, we correct the arrival times for each receiver function to a single reference ray parameter $(0.0573 \mathrm{~s} / \mathrm{km})$, equivalent to an epicentral distance of $67^{\circ}$ and a focal depth of $33 \mathrm{~km}$. The identification of the P410s and P660s converted phases is confirmed because we observe the correct moveout for these phases.

The teleseismic arrivals analyzed span a wide range of ray parameters and back azimuths and thus sample a $700-\mathrm{km}^{2}$ area of the transition zone (Fig. 3). In an initial effort to investigate the spatial variations in the thickness of the mantle transition zone, we pick the P410s and P660s arrivals for individual receiver functions and plot the magnitude of the P660s-P410s differential travel time (which is proportional to the thickness of the mantle transition zone) at the point where the wave path pierces the $660-\mathrm{km}$ mantle discontinuity (Fig. 3). Though the individual differential times show substantial scatter, a region in which the spatially averaged thickness of the transition zone is significantly less than normal is centered at $91.7 \pm 0.8^{\circ} \mathrm{W}, 0.7 \pm 0.8^{\circ} \mathrm{S}$, approximately $40 \mathrm{~km}$ southwest of the center of the island of Fernandina.

To resolve more clearly the depths of the mantle discontinuities, we use a stacking method to enhance the P410s and P660s phases. A stack of all 190 receiver functions ('All Galápagos') with

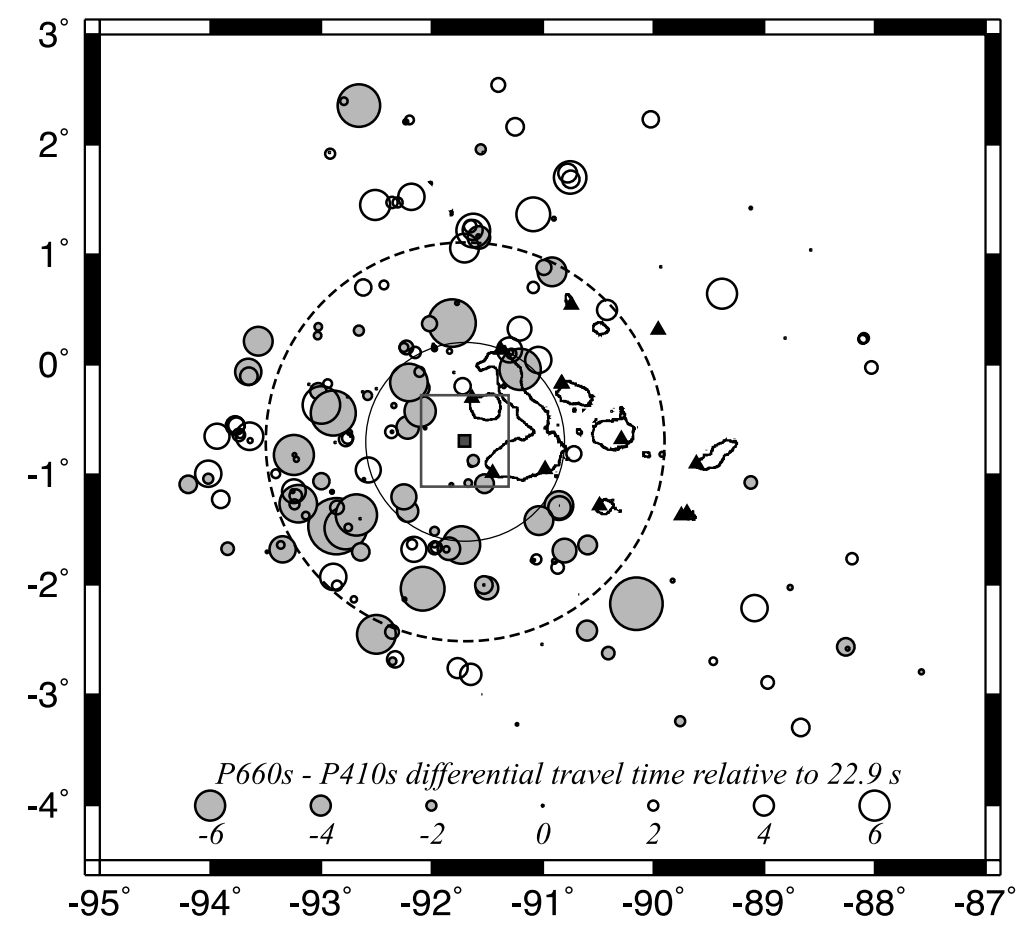

Fig. 3. Transition zone locations sampled by each receiver function. The locations (circles) correspond to the piercing points at $660 \mathrm{~km}$ depth, and the P660s-P410s differential travel time is shown relative to $22.9 \mathrm{~s}$ by the symbol size. A region in which the spatially averaged thickness of the transition zone is significantly less than normal is centered at approximately $91.7 \pm 0.8^{\circ} \mathrm{W}$, $0.7 \pm 0.8^{\circ} \mathrm{S}$ (square with outlining square showing the uncertainty). The circles are concentric to this point and have radii of 100 $\mathrm{km}$ (solid line) and $200 \mathrm{~km}$ (dashed line). Triangles show the locations of seismic stations. 


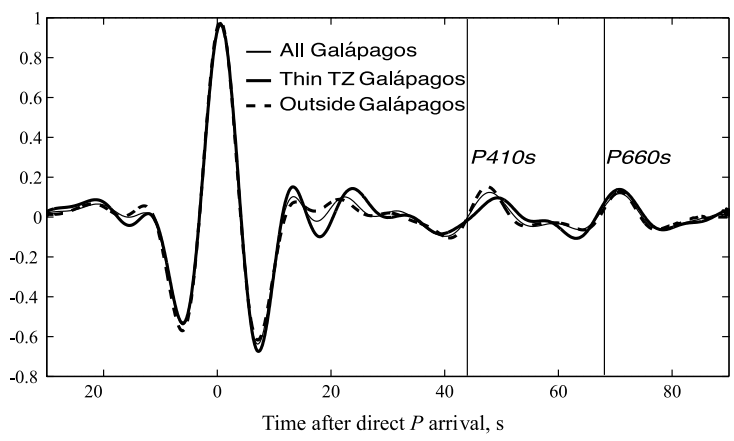

Fig. 4. Stacked radial receiver functions for the full dataset (All Galápagos; light trace) and two subsets of the data that include wave paths that pierce the $660-\mathrm{km}$ mantle transition zone at distances less than $100 \mathrm{~km}$ (Thin TZ Galápagos; heavy line) and at distances from 200 to $450 \mathrm{~km}$ (Outside Galápagos; heavy dashed trace) from the center of the region of anomalously thin transition zone. All receiver functions are corrected for normal moveout, and the direct $\mathrm{P}$-wave amplitude is normalized to unity. All stacks show clear conversions from both the 410 - and $660-\mathrm{km}$ discontinuities. Vertical lines indicate the P410s and P660s arrival times predicted by the modified iasp91 reference model. The observed arrivals of both converted phases are late relative to the predictions. Compared with the Outside Galápagos stack, the Thin TZ Galápagos stack has P410s and P660s arrivals which are closer together in time by $1.8 \pm 0.8 \mathrm{~s}$.

the normal-moveout correction applied (Fig. 4) shows clear converted phases from both the 410and $660-\mathrm{km}$ discontinuities with amplitudes of $10 \pm 2 \%$ of the initial $\mathrm{P}$ arrival. The P410s and $\mathrm{P} 660$ s arrival times and their uncertainties are determined by randomly selecting $50 \%$ of the receiver functions contributing to this stack. These selected receiver functions are stacked, and the times of the peaks of the P410s and P660s arrivals are picked; this procedure is repeated 50 times. The mean of the 50 picked arrival times and their standard deviation gives the arrival time and its uncertainty for the complete stack. For the full data set the arrival times of the P410s and P660s phases, relative to the direct $\mathrm{P}$ arrival, are $47.9 \pm 0.3 \mathrm{~s}$ and $70.8 \pm 0.2 \mathrm{~s}$, respectively. Both of the converted phases arrive later than predicted by the modified iasp91 model $(44.0$ and $68.0 \mathrm{~s}$, respectively), a result indicating the presence of anomalously low seismic velocities in the upper mantle (i.e., shallower than $410 \mathrm{~km}$ depth) beneath the Galápagos.

The spatial variation in the depth of the 410and $660-\mathrm{km}$ mantle discontinuities is revealed when the receiver functions are binned and stacked by the distance of their associated piercing point at $660 \mathrm{~km}$ depth from the center of transition zone thinning in bins of width $50 \mathrm{~km}$ from zero to $450 \mathrm{~km}$ (Fig. 5). These variations are quantified in Table 1, which gives converted phase arrival times and their uncertainties for stacks of receiver functions for wave paths with $660-\mathrm{km}$ piercing points that are at distances from the center of transition zone thinning less than 50, 100, 150 , and $200 \mathrm{~km}$ and $200-450 \mathrm{~km}$. Clear arrivals corresponding to the 410 - and $660-\mathrm{km}$ discontinuities can be seen at all distances. At distances less than $50 \mathrm{~km}$, however, there are only nine receiver functions, and the P410s arrival time is strongly variable and consequently has a large uncertainty. At all distances, the observed P410s and P660s phases arrive late relative to the predictions of the modified iasp91 model. For distances less than $100 \mathrm{~km}$ from the center of the anomalously thin transition zone the P410s arrival time is the greatest, $49.2 \pm 0.6 \mathrm{~s}$. As the maximum distance from the center of transition zone thinning is increased, the stacked P410s arrival time decreases

Table 1

$\mathrm{P} 660$ s and $\mathrm{P} 410$ s arrival times (relative to $\mathrm{P}$ arrival times) inferred from stacks of radial receiver functions (RF5) sorted by distance from the center of transition zone thinning

\begin{tabular}{lcllll}
\hline Distance range: Stack name & \# RFs & $\begin{array}{l}\text { P410s } \\
\text { (s) }\end{array}$ & $\begin{array}{l}\text { P660s } \\
\text { (s) }\end{array}$ & $\begin{array}{l}\text { P410s+P660s } \\
\text { (s) }\end{array}$ & $\begin{array}{l}\text { P660s-P410s } \\
\text { (s) }\end{array}$ \\
\hline 0-450 km: All Galápagos & 190 & $47.9 \pm 0.3$ & $70.8 \pm 0.2$ & $118.7 \pm 0.4$ & $22.9 \pm 0.4$ \\
$<50 \mathrm{~km}$ & 9 & $50.0 \pm 2.4$ & $71.4 \pm 0.7$ & $121.4 \pm 2.5$ & $21.4 \pm 2.5$ \\
$<100 \mathrm{~km}$ : Thin TZ Galápagos & 36 & $49.2 \pm 0.6$ & $70.6 \pm 0.4$ & $119.8 \pm 0.7$ & $21.4 \pm 0.7$ \\
$<150 \mathrm{~km}$ & 85 & $48.8 \pm 0.6$ & $70.6 \pm 0.3$ & $119.4 \pm 0.7$ & $21.8 \pm 0.7$ \\
$<200 \mathrm{~km}$ & 111 & $48.5 \pm 0.4$ & $70.8 \pm 0.2$ & $119.3 \pm 0.4$ & $22.2 \pm 0.4$ \\
$200-450 \mathrm{~km}:$ Outside Galápagos & 79 & $47.4 \pm 0.2$ & $70.7 \pm 0.3$ & $118.2 \pm 0.4$ & $23.2 \pm 0.4$ \\
\hline
\end{tabular}


(a)
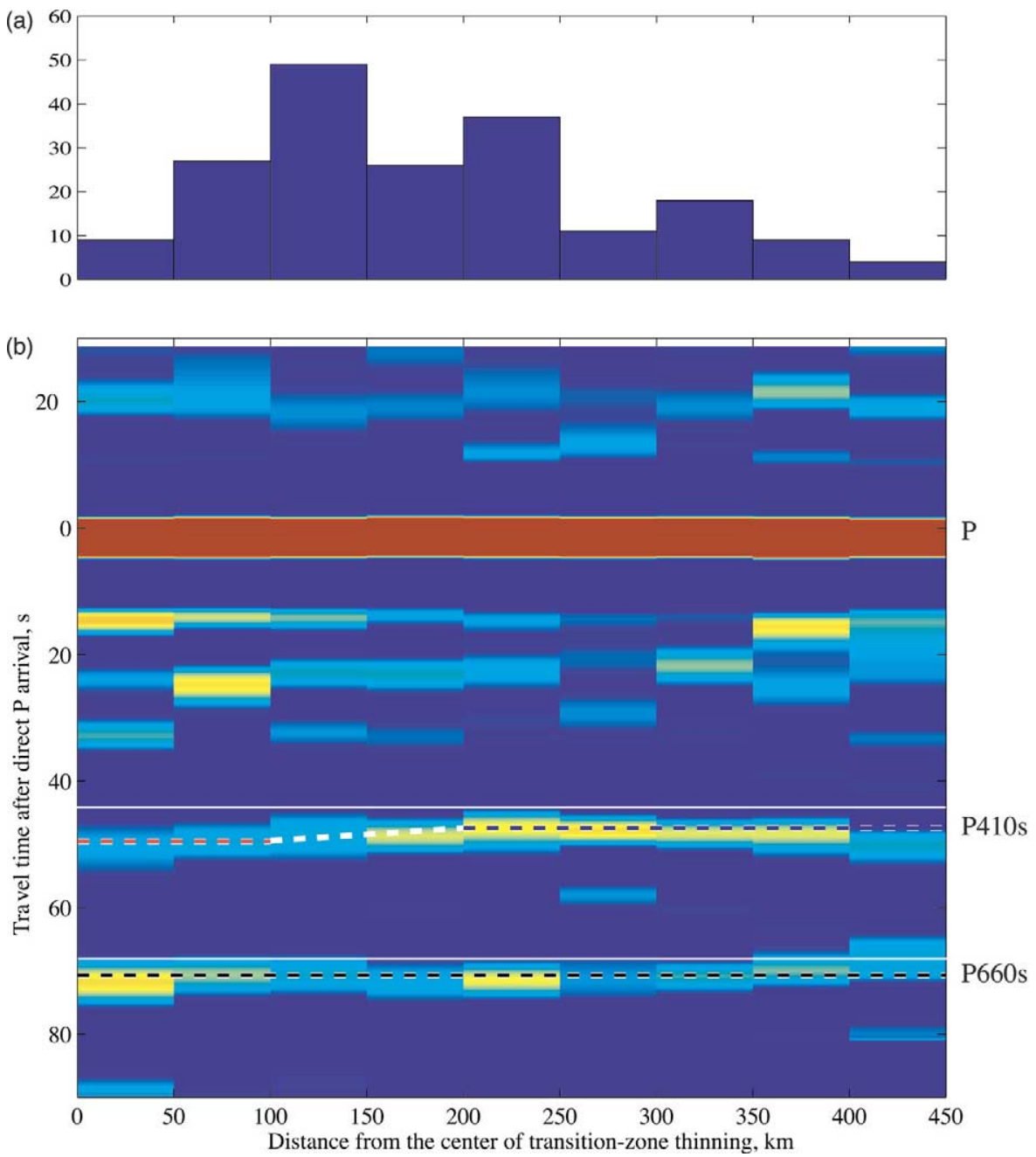

Fig. 5. Receiver functions binned and stacked by distance from the center of transition zone thinning in bins of width $50 \mathrm{~km}$. (a) Number of receiver functions per bin. (b) Color image of the amplitude of stacked receiver functions for each bin. Green-yellow colors show positive values, while dark blue represents values below zero. Dashed lines show the arrival times for the P-to-S conversions from $410 \mathrm{~km}$ (red for distances less than $100 \mathrm{~km}$ and blue for distances from 200 to $450 \mathrm{~km}$; white is a linear approximation to the decrease in arrival time from 100 to $200 \mathrm{~km}$ ) and $660 \mathrm{~km}$ (black for all distances). The P410s and P660s arrival times predicted by the modified iasp91 reference model are shown as thin white lines.

steadily to a value of $47.4 \pm 0.2 \mathrm{~s}$ for the stack of receiver functions at distances from 200 to 450 $\mathrm{km}$. At all distances, the P660s phase arrival time does not vary significantly from a mean value of $70.6 \pm 0.3 \mathrm{~s}$.

To determine the maximum variation in mantle discontinuity depth beneath the Galápagos, we compare stacked receiver functions for wave paths that pierce the $660-\mathrm{km}$ mantle discontinuity at distances less than $100 \mathrm{~km}$ from the center of transition zone thinning ('Thin TZ Galápagos') with a stack of receiver functions for wave paths that pierce the $660-\mathrm{km}$ mantle discontinuity at distances from 200 to $450 \mathrm{~km}$ ('Outside Galápagos') (Fig. 4 and Table 1). Compared with the Outside Galápagos dataset, the Thin TZ Galápa- 
gos P410s phase arrives late $(49.2 \pm 0.6 \mathrm{~s}$ versus $47.4 \pm 0.2 \mathrm{~s})$ while the P660s arrival time does not differ significantly $(70.6 \pm 0.4 \mathrm{~s}$ versus $70.7 \pm$ $0.3 \mathrm{~s})$.

Because the arrival times of the converted phases are influenced by upper mantle velocity as well as the thickness of the transition zone, we isolate the effect of the mantle shallower than $410 \mathrm{~km}$ by plotting in Fig. 6 the differential $\mathrm{P} 660 \mathrm{~s}-\mathrm{P} 410 \mathrm{~s}$ arrival time versus the summed $\mathrm{P} 410 \mathrm{~s}+\mathrm{P} 660 \mathrm{~s}$ arrival time relative to the P-wave. In this coordinate system, a decrease in the thickness of the transition zone lessens the P660sP410s time, whereas a decrease in upper mantle velocities increases the P410s+P660s time. The transition zone thickness of the iasp91 reference model corresponds to a P660s-P410s time of 24.0 s. The P410s+P660s time for the same model is $112.0 \mathrm{~s}$ (open circle in Fig. 6). While the P660s $-P 410$ s time of $23.2 \pm 0.4 \mathrm{~s}$ for the Outside Galápagos dataset is smaller than that predicted by iasp91, it is not resolvably different from that determined for the Pacific basin from SS precursor arrival times [32], indicating that the transition zone thickness averaged over a broad area around the Galápagos is similar to that of the Pacific basin in general. In contrast, the observed P660s-P410s time $(21.4 \pm 0.7 \mathrm{~s})$ for the Thin TZ Galápagos dataset is significantly less than that of the Pacific basin and that predicted for iasp91. The observed P410s+P660s times for both sets of data are greater than for the iasp91 model. Compared with the Outside Galápagos dataset, the Thin TZ Galápagos P410s+P660s time is slightly larger $(119.8 \pm 0.7 \mathrm{~s}$ versus $118.2 \pm 0.4 \mathrm{~s})$. These results indicate that while upper mantle velocities are generally low beneath the entire archipelago, an anomalously thin transition zone and somewhat more reduced upper mantle velocities are found in the Thin TZ Galápagos region, which lies within $100 \mathrm{~km}$ of the center of transition zone thinning.

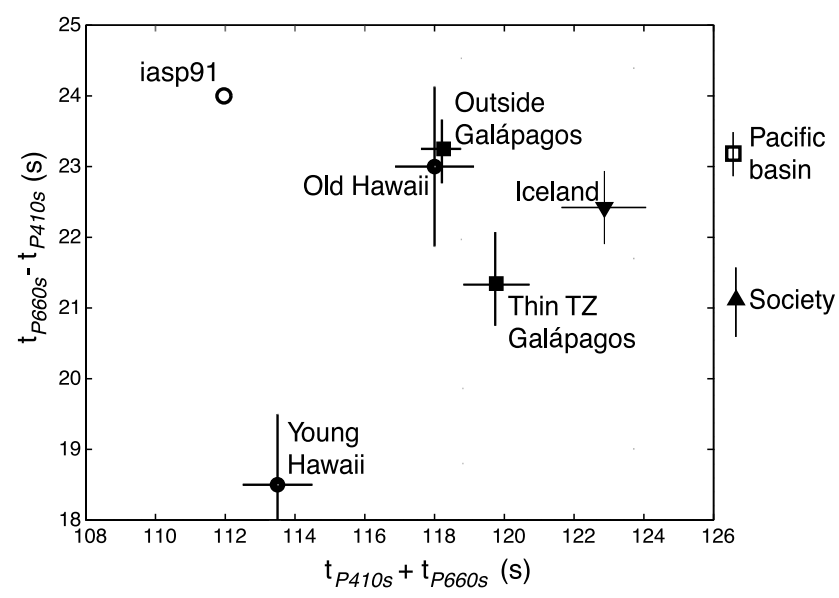

Fig. 6. Comparison of P660s-P410s differential time versus summed P410s+P660s time for our data (squares) with those for the iasp91 Earth model (open circle) and for several other hotspots, as well as a comparable result for the Pacific basin. 'Outside Galápagos' denotes receiver functions for wave paths that pierce the $660-\mathrm{km}$ mantle discontinuity at distances from 200 to 450 $\mathrm{km}$ from the center of mantle transition zone thinning, while 'Thin TZ Galápagos' denotes receiver functions for wave paths that pierce the $660-\mathrm{km}$ mantle discontinuity at distances less than $100 \mathrm{~km}$ from the center of mantle transition zone thinning. The transition zone thickness inferred from SS precursor arrival times for the Pacific basin (open square) [34] and for the Society hotspot (triangle) [22] have been converted to P660s-P410s differential time and are shown to the right of the figure as there is no comparable P410s+P660s time. Other hotspot data shown are Iceland [18] (inverted triangle) and Hawaii (circles; 'Young Hawaii' and 'Old Hawaii' correspond to KIP and HIBSN, respectively) [16]. Oceanic sites generally have summed P410s+P660s times greater than the reference Earth model, indicative of low-velocity upper mantle. Differential P660s-P410s times beneath the Galápagos, Hawaii, Iceland, and Society hotspots all lie significantly below that for the average Earth, indicating a thinner than normal mantle transition zone. 


\section{Anomalous transition zone structure}

Variations in the P660s-P410s differential times may be used to infer changes in the thickness of the mantle transition zone. A 1-s change in the P660s-P410s differential time corresponds to about a $10-\mathrm{km}$ change in the thickness of the transition zone. For the Thin TZ Galápagos region the P660s-P410s differential time is $2.6 \pm$ $0.7 \mathrm{~s}$ less than for iasp91 and $1.8 \pm 0.8 \mathrm{~s}$ less than the surrounding area represented by the Outside Galápagos dataset (Fig. 6). Thus, the transition zone beneath the Thin TZ Galápagos is $18 \pm 8 \mathrm{~km}$ thinner than the regional average and $26 \pm 7 \mathrm{~km}$ thinner than the transition zone's average thickness over the whole Earth.

Our results on the seismic structure of the Galápagos transition zone bear on the role of compositional and thermal effects in generating excess mantle melting beneath oceanic hotspots. Given the strength of the observed converted phases (amplitudes $\sim 10 \%$ of the direct arrival), it is unlikely that variations in the thickness of the mantle transition zone are the result of variations in composition alone. Water in excess of $220 \mathrm{ppm}$ by weight is expected to move the phase transition at $410 \mathrm{~km}$ depth to shallower depths and to increase the depth over which this phase transition occurs, resulting in a weaker seismic conversion [33]. The low coherence of the P410s arrivals observed at piercing-point distances less than $50 \mathrm{~km}$ from the center of transition zone thinning may be due to the presence of water in the mantle, an inference that is consistent with mantle $\mathrm{H}_{2} \mathrm{O}$ contents of up to $300 \mathrm{ppm}$ beneath the Galápagos Spreading Center [13]. At the same time, a mantle thermal anomaly must extend down to at least $410 \mathrm{~km}$ depth to account for both the observed increase in P410s+P660s time and the decrease in P660s-P410s time. The strong P660s phases observed suggest that garnet is not sufficiently abundant in the mantle for the seismic effect of the garnet-majorite phase transition to counteract that of the phase transition of $(\mathrm{Mg}, \mathrm{Fe})_{2} \mathrm{SiO}_{4}$ ringwoodite to $(\mathrm{Mg}, \mathrm{Fe}) \mathrm{SiO}_{3}$ perovskite plus magnesiowüstite [34]. Thus, the most straightforward explanation of these results is that the change in transition zone thickness is due to anomalously high temperatures at depths greater than $410 \mathrm{~km}$.

\section{Concluding discussion}

We attribute the observed variation in transition zone thickness beneath the Galápagos to a localized thermal anomaly associated with a mantle plume. The $410-\mathrm{km}(610-\mathrm{km})$ discontinuity has a positive (negative) Clapeyron slope of 2.5-2.9 $\mathrm{MPa} \mathrm{K}^{-1}\left(-2.0\right.$ to $\left.-3.0 \mathrm{MPa} \mathrm{K}^{-1}\right)$ [14]. Thus a 1 -s change in P660s-P410s travel time corresponds to a temperature difference of about $70 \pm 10 \mathrm{~K}$ [14]. If the variations in transition zone topography observed at the Galápagos are entirely due to a thermal plume that passes through both discontinuities, the temperature excess is $130 \pm 60 \mathrm{~K}$ relative to the surrounding region or $180 \pm 55 \mathrm{~K}$ relative to the average Earth.

Beneath the Galápagos the thermal plume associated with mantle upwelling extends to depths greater than $410 \mathrm{~km}$. If the Galápagos plume originates at the $660-\mathrm{km}$ discontinuity and, by inference, the observed P660s-P410s time is entirely due to deepening of the $410-\mathrm{km}$ discontinuity, then the required temperature excess would be approximately $125-365 \mathrm{~K}$. This temperature anomaly is almost twice that required for a plume that originates in the lower mantle. The data presented here, however do not allow us to distinguish unequivocally between a transition-zone and a lower mantle origin for the Galápagos plume.

While Fernandina has often been considered to overlie the Galápagos plume (e.g., [35]), our results suggest that the plume is located $40 \mathrm{~km}$ to the southwest of the center of this island and has a radial extent of about $100 \mathrm{~km}$ (Fig. 1). This inference is supported by the fact that, though Fernandina is usually thought to be the most active volcano of the Galápagos group, Sierra Negra has had much more voluminous eruptions over the past few decades and is a much larger edifice (Dennis Geist, personal communication, 2003). In addition, the highest ${ }^{3} \mathrm{He} /{ }^{4} \mathrm{He}$ ratios are found both at Fernandina and to the south- 
east at Vulcan Sierra Negra on the island of Isabela (near G08) [26,27].

The limited size of the Galápagos plume at the mantle transition zone compared with the diffuse volcanism in the Galápagos archipelago, points to the role of plate motion and plume-ridge interactions in modulating mantle flow and melt generation in the upper mantle. While the anomalously thin region of the mantle transition zone is observed to be spatially restricted, active volcanism in the Galápagos occurs to the east and north of this region. This pattern implies that the ascending mantle can be deflected eastward by the motion of the Nazca plate over the plume [36] (large arrow, Fig. 1) and that it can also be transported northward to the Galápagos Spreading Center by interaction of the plume with the ridge.

The structure of the transition zone surrounding the Galápagos is comparable to other oceanic areas. Broad areas surrounding Hawaii [18] and the Galápagos (Fig. 6) are characterized by low upper mantle velocities and a generally normal thickness of the transition zone. These observations agree with the transition zone thickness inferred for the Pacific basin from SS precursor arrival times [32].

In contrast, within more limited areas beneath several oceanic hotspots, including the Galápagos, the transition zone is markedly thinned (Fig. 6). Receiver function data from the Galápagos and Iceland $[15,17,20]$ are consistent with both low upper mantle velocities and thinning of the transition zone in regions near the presumed location of plume upwelling. In addition, an SS precursor study at the Society hotspot also shows thinning of the transition zone [24]. In the case of Hawaii, however, receiver functions that sample the mantle near the presumed location of plume upwelling indicate a substantially thinned transition zone but upper mantle velocities that are only slightly reduced from the normal value. The P660s $-\mathrm{P} 410 \mathrm{~s}$ time of the Thin TZ Galápagos dataset (21.4 \pm $0.7 \mathrm{~s}$ ) is similar to that determined for Iceland and inferred for the Society hotspot. On the basis of these results we conclude that the thermal anomaly inferred for the Galápagos $(130 \pm 60 \mathrm{~K})$ is comparable that beneath the Iceland and Society hotspots $[15,17,20,24]$, while the thermal anomaly of the Hawaiian plume [18] is about twice as large.

\section{Acknowledgements}

We thank M.L. Hall, D.E. James, the Charles Darwin Research Station, and the Parque Nacional Galápagos for their logistical support and advice. We also thank the crew of the Española and the Beagle for navigating the islands. We are very grateful to Pat Ryan, Peter Burkett, and Randy Kuehnel for their technical support and to C. Bryant, B. Burdick, E. Burkett, S. George, D.E. James, K. James, A. Kuehnel, D. Schutt, and D. Villagómez for help in the field. Dennis Geist, Gabriele Marquart and an anonymous reviewer provided comments that improved this manuscript. This research has been supported by the National Science Foundation under Grants OCE-9908695 and OCE-0221549.[SK]

\section{References}

[1] W.J. Morgan, Plate motions and deep convection, Geol. Soc. Am. Mem. 132 (1972) 7-22.

[2] N.H. Sleep, Hotspots and mantle plumes: some phenomenology, J. Geophys. Res. 95 (1990) 6715-6736.

[3] J. Ritsema, H.J. van Heijst, J.H. Woodhouse, Complex shear wave velocity structure imaged beneath Africa and Iceland, Science 286 (1999) 1925-1928.

[4] D. Helmberger, S. Ni, L. Wen, J. Ritsema, Seismic evidence for ultralow-velocity zones beneath Africa and eastern Atlantic, J. Geophys. Res. 105 (2000) 23,865-23,878.

[5] A. Hofmann, Mantle geochemistry; the message from oceanic volcanism, Nature 385 (1997) 219-229.

[6] M.K. McNutt, D.W. Caress, J. Reynolds, K.A. Jordhal, R.A. Duncan, Failure of plume theory to explain midplate volcanism in the southern Austral Islands, Nature 389 (1997) 479-482.

[7] V. Clouard, A. Bonneville, How many Pacific hotspots are fed by deep-mantle plumes?, Geology 29 (2001) 695-698.

[8] D.L. Turcotte, E.R. Oxburgh, Mid-plate tectonics, Nature 244 (1973) 337-339.

[9] D.L. Anderson, The thermal state of the upper mantle: no role for mantle plumes, Geophys. Res. Lett. 27 (2000) 3623-3626.

[10] V. Courtillot, A. Davaille, J. Besse, J. Stock, Three distinct types of hotspots in the Earth's mantle, Earth Planet. Sci. Lett. 205 (2003) 295-308. 
[11] J.-G. Schilling, R.H. Kingsley, J.D. Devine, Galapagos hotspot spreading center system, 1, Spatial petrological and geochemical variations $\left(83^{\circ} \mathrm{W}-101^{\circ} \mathrm{W}\right)$, J. Geophys. Res. 87 (1982) 5593-5610.

[12] E. Bonatti, Not so hot 'hot spots' in the oceanic mantle, Science 250 (1990) 107-111.

[13] P.D. Asimow, C.H. Langmuir, The importance of water to oceanic mantle melting regimes, Nature 421 (2003) 815-820.

[14] C.R. Bina, G. Helfrich, Phase transition Clapeyron slopes and transition zone seismic discontinuity topography, J. Geophys. Res. 99 (1994) 15,853-15,860.

[15] Y. Shen, S.C. Solomon, I.Th. Bjarnason, G.M. Purdy, Hot mantle transition zone beneath Iceland and the adjacent Mid-Atlantic Ridge inferred from P-to-S conversions at the $410-$ and $660-\mathrm{km}$ discontinuities, Geophys. Res. Lett. 23 (1996) 3527-3530.

[16] K.G. Dueker, A.F. Sheehan, Mantle discontinuity structure from midpoint stacks of converted $\mathrm{P}$ to $\mathrm{S}$ waves across the Yellowstone hotspot track, J. Geophys. Res. 102 (1997) 8313-8327.

[17] Y. Shen, S.C. Solomon, I.Th. Bjarnason, C.J. Wolfe, Seismic evidence for a lower mantle origin of the Iceland mantle plume, Nature 395 (1998) 62-65.

[18] X. Li, R. Kind, K. Priestley, S.V. Sobolev, F. Tilmann, X. Yuan, M. Weber, Mapping the Hawaiian plume conduit with converted seismic waves, Nature 405 (2000) 938-941.

[19] A.F. Sheehan, P.M. Shearer, H.J. Gilbert, K.G. Dueker, Seismic migration processing of P-SV converted phases from mantle discontinuity structure beneath the Snake River Plain, western United States, J. Geophys. Res. 105 (2000) 19,055-19,065.

[20] Y. Shen, S.C. Solomon, I.Th. Bjarnason, G. Nolet, J.W. Morgan, R.M. Allen, K. Vogfjörd, S. Jakobsdóttir, R. Stefánsson, B.R. Julian, G.R. Foulger, Seismic evidence for a tilted mantle plume and north-south mantle flow beneath Iceland, Earth Planet. Sci. Lett. 197 (2002) 261272.

[21] X. Li, R. Kind, X. Yuan, Seismic study of upper mantle and transition zone structure beneath hotspots, Phys. Earth Planet. Inter. 136 (2003) 79-92.

[22] C.J. Wolfe, I.Th. Bjarnason, J.C. VanDecar, S.C. Solomon, Seismic structure of the Iceland mantle plume, Nature 385 (1997) 245-247.

[23] R.M. Allen, G. Nolet, W.J. Morgan, K. Vogfjörd, B.H. Bergsson, P. Erlendsson, G.R. Foulger, S. Jakobsdóttir, B.R. Julian, M. Pritchard, S. Ragnarsson, R. Stefánsson,
Imaging the mantle beneath Iceland using integrated seismological techniques, J. Geophys. Res. 107 (2002) 2325, 10.1029/2001JB000595.

[24] F. Niu, S.C. Solomon, P.G. Silver, D. Suetsugu, H. Inoue, Mantle transition-zone structure beneath the South Pacific Superswell and evidence for a mantle plume underlying the Society hotspot, Earth Planet. Sci. Lett. 198 (2002) 371-380.

[25] C.J. Wolfe, I.Th. Bjarnason, J.C. VanDecar, S.C. Solomon, Assessing the depth resolution of tomographic models for the upper mantle structure beneath Iceland, Geophys. Res. Lett. 29 (2002) 10.1029/2001GL013657.

[26] D.W. Graham, D.M. Christie, K.S. Harpp, J.E. Lupton, Mantle plume helium in submarine basalts from the Galápagos Platform, Science 262 (1993) 2023-2026.

[27] M.D. Kurz, D. Geist, Dynamics of the Galápagos hotspot from helium isotope geochemistry, Geochim. Cosmochim. Acta 63 (1999) 4139-4156.

[28] C.A. Langston, Structure under Mount Rainier, Washington, inferred from teleseismic body waves, J. Geophys. Res. 84 (1979) 4749-4762.

[29] C.J. Ammon, The isolation of receiver effects from teleseismic P waveforms, Bull. Seismol. Soc. Am. 81 (1991) 2504-2510.

[30] S. van der Lee, H. Paulssen, G. Nolet, Variability of P660s phases as a consequence of topography of the 660 km discontinuity, Phys. Earth Planet. Inter. 86 (1994) 147-164.

[31] B.L.N. Kennett, E.R. Engdahl, Travel times for global earthquake location and phase identification, Geophys. J. Int. 105 (1991) 429-466.

[32] M.P. Flanagan, P.M. Shearer, Global mapping of topography on transition zone velocity discontinuities by stacking SS precursors, J. Geophys. Res. 103 (1998) 2673-2692.

[33] B.J. Wood, The effect of $\mathrm{H}_{2} \mathrm{O}$ on the 410-kilometer seismic discontinuity, Science 268 (1995) 75-76.

[34] D.J. Weidner, Y. Wang, Chemical- and Clapeyron-induced buoyancy at the $660 \mathrm{~km}$ discontinuity, J. Geophys. Res. 103 (1998) 7431-7441.

[35] J.F. Allen, T. Simkin, Fernandina Volcano's evolved, well-mixed basalts; mineralogical and petrological constraints on the nature of the Galapagos plume, J. Geophys. Res. 105 (2000) 6017-6041.

[36] A.E. Gripp, R.G. Gordon, Current plate velocities relative to the hotspots incorporating the NUVEL-1 global plate motion model, Geophys. Res. Lett. 17 (1990) 1109 1112. 